\title{
Projeto de educação da cidade de carapicuíba - formação e cidadania
}

\section{Carapicuíba city education project, formation and citizenship}

DOI: $10.46814 /$ lajdv3n4-024

Recebimento dos originais: 01/05/2021

Aceitação para publicação: 31/06/2021

Prof. Ms. Aparecida Graça Carlos

Secretaria Municipal de Educação do Município de Carapicuíba - Brasil

E-mail: semeduc.carapicuiba@gmail.com

Prof. Ms. Katsue Hamada e Zenun

NAP Escola do Futuro/USP - Brasil

E-mail: katsuezenun@gmail.com

Prof. Ms. Mônica Markunas

LAGE/UNICAMP - Brasil

E-mail: monica.markunas@uol.com.br

\section{RESUMO}

Em 2009, a Secretaria Municipal de Educação de Carapicuíba, na região metropolitana de São Paulo, iniciou a elaboração de seu Plano Curricular, fundamentado em teorias interacionistas de Currículo, buscando a identidade de sua Rede de Ensino, valorizando a realidade e a cultura local. Em 2013, o projeto ampliou areflexão sobre as estruturas do sistema; retomou conceitos norteadores como conhecimento, abordagem metodológica e avaliação; bem como trouxe a discussão sobre reorganização das disciplinas em áreas do conhecimento, determinando a seleçãoe distribuição dos conteúdos o que demanda também a reorganização dos tempos e espaços escolares.

Palavras,chave: políticas públicas, formação continuada, currículo

\section{ABSTRACT}

In 2009, the Municipal Department of Education of Carapicuíba, in the metropolitan region of São Paulo, started the development of its Curriculum Plan, based on interactionist theories of Curriculum, seeking the identity of its Education Network, valuing the reality and the local culture. In 2013, the project expanded the reflection on the system's structures; resumed guiding concepts such as knowledge, methodological approach and evaluation; as well as brought the discussion about reorganization of disciplines in areas of knowledge, determining the selection and distribution of content which also demands the reorganization of school times and spaces.

Keywords: public policies, continuing education, curriculum.

\section{INTRODUÇÃO}

Carapicuíba é um município da Região Metropolitana de São Paulo originado de uma das doze aldeias fundadas pelo Pe. José de Anchieta, por volta de 1580, no início do processo da colonização portuguesa na América. Até meados da década de 1950, manteve-se como pequeno 
núcleo urbano. A partir de então, com a expansão de um modelo de desenvolvimento econômico pautado na indústria e no transporte rodoviário, em 1965, seu território foi desmembrado de Barueri e começou a passar por um rápido processo de ocupação. Na década de 1970 o município recebeu um grande número de migrantes, atraídos principalmente pela oferta de empregos nas indústrias da capital paulista. Paralelamente a esse período de expansão econômica, ocorreu no Brasil

uma reforma educacional que iniciou a obrigatoriedade do ensino fundamental de 8 anos.

Conforme o censo populacional de 2010, o município contava com 377.622 habitantes, dos quais 88.625 estão matriculados em todos os níveis de ensino ${ }^{1}$, assim distribuídos: 13.743 na Educação Infantil (creche e pré-escola), 52.350 no Ensino Fundamental (anos iniciais e anos finais) e 3.446 na Educação de Jovens e Adultos ${ }^{2}$.

Frente à universalização do acesso à educação e à grande diversidade populacional existente no município, surgiram outros desafios, como a expansão do ensino de qualidade para todas as faixas etárias.

Assim, o atual governo municipal tem investido na ampliação e reforma de sua rede física de escolas, buscando garantir o direito de acesso e permanência na escola de toda a população em idade escolar, bem como tem promovido eventos de formação continuada de professores. Desde 2009, abriu o debate sobre um plano de carreira para omagistério e a elaboração de um currículo escolar para sua rede. É deste último tópico que trataremos no presente texto.

Para o trabalho de formação continuada e a elaboração do currículo de sua rede, considerouse que as pesquisas recentes sobre a importância da educação, responsabilidade das diferentes esferas da sociedade, atribuem às escolas o papel fundamental na construção do conhecimento, pois é nesses espaços que se viabilizam as especificidades da educação escolar, possibilitando aos alunos acesso e apropriação dos conhecimentos acumulados pela humanidade. Estão envolvidos nesse processo, tanto os alunos e professores quanto a equipe escolar e os pais, além da comunidade local. É por meio do esforço conjunto que se torna possível a apreensão da realidade, sua leitura e releitura, para, enfim, a produção de novos conhecimentos.

Assim, a produção de novos conhecimentos está fundada principalmente nos processos de investigação que promovem a superação do senso comum e a apropriaçãodos procedimentos de pesquisa, cuja sistematização contribui para a elaboração de novos estudos. Dessa forma, ganham relevância os processos de ensino e aprendizagemporque requerem da escola e de seus profissionais

\footnotetext{
${ }^{1}$ Dados de 2013 - Instituto Nacional de Estudos e Pesquisas Educacionais Anísio Teixeira (Inep),disponível em http://portal.inep.gov.br/basica-censo-escolar-matricula, acesso em 25.11.2013.

${ }^{2} \mathrm{O}$ Ensino Médio e Profissionalizante não são de responsabilidade do Município, sendo atendidos poroutras redes de ensino.
} 
clareza quanto aos fins da educação, os pressupostos teóricos e os conteúdos específicos para sua viabilização. São realidades multifacetadas movidas por conflitos de origens diversas, mas que buscam naeducação escolar as chances para superar sua condição ao mesmo tempo em que também a escola busca proporcionar aos alunos competências que lhes possibilitem intervir e participar nas transformações dessas realidades.

\section{FORMAÇÃO DE PROFESSORES}

Desde os anos 60, as pesquisas e estudos sobre a formação de professores no Brasil vêm apontando a falta de habilidades e competências do professor para investigara própria prática. Tais habilidades e competências tornam-se necessárias, especialmente durante o processo de democratização do acesso à escola e a consequente entrada no sistema de crianças e jovens oriundos das camadas populares, o que faz com que a prática pedagógica se depare crescentemente com desafios mais complexos.

A nova Lei de Diretrizes e Bases de 1996 refere-se à pesquisa enquanto inerente às diferentes modalidades de ensino, mas a enfatiza como primordial no ensino superior e especificamente na área de formação de professores e demais licenciaturas, considerada como finalidade.

No entanto, apesar dessa orientação ficar relegada a um segundo plano na maioria dos cursos de formação de professores, entendemos a sua importância, isto é, é preciso formar um profissional que reflita na e sobre a ação para poder tomar decisões. Um forte componente de reflexão, pois quanto mais nos defrontamos com tarefas complexas, mais é preciso avaliar a pertinência de tal ou qual método, combinar vários,e até mesmo inventá-los para fazer frente à singularidade da situação.

O profissional formado deve ir além da formação baseada não apenas na ciência aplicada, mas na prática reflexiva, ou seja, não se trata de conhecermos primeiroa teoria para posteriormente aplicá-la aos problemas da prática, mas sim, com o auxílio da teoria, dos conhecimentos científicos, problematizarmos as experiências para buscara raiz, colocando os problemas de uma nova forma. Criar não apenas formas de resolveros problemas da prática, mas de compreendê-los para mudar a prática, pois formar para a prática reflexiva significa, sobretudo, tornar a reflexão uma rotina da vida cotidiana - ohábito de duvidar, de se espantar, de perguntar, de ler, de anotar algumas questões, de debater, de refletir em voz alta, dentre outros, a levantar hipóteses, a seguir intuições, a enfrentar contradições, enfim, aprender a operar e mesmo brincar com as ideias.

Para tanto, o trabalho em Carapicuíba baseia-se em duas perspectivas fundamentais: a pesquisa na formação de professores e a formação continuada baseada em princípios e diretrizes norteadores de um Currículo que busque, acima de tudo, contribuir na superação das desigualdades, do fracasso escolar e possibilite educação dequalidade para todos. 


\section{PESQUISA E A FORMAÇÃO DE PROFESSORES}

A Lei de Diretrizes e Bases de 1996 apresenta dispositivos que buscam incentivar o trabalho de pesquisa e investigação científica, visando desenvolvimento da ciência e da tecnologia e da criação e difusão da cultura, e desse modo, desenvolver o entendimento do homem e do meio em que vive.

$\mathrm{Na}$ prática, isso significa possibilitar a reflexão sobre a práxis que, desenvolvida de modo específico, possibilita a criação de uma “comunidade crítica de professores", alimentados por saberes acadêmicos ou profissionais, que aguçados pelo olhar investigativo e vinculados a outros saberes "teorizar a experiência" - possibilita também a formação de professores inconformados com o aluno que está em dificuldades, que o trabalho de um ano inteiro não resulte em nenhum avanço e, pelo seu inconformismo batalham, tentam outras maneiras de fazer, buscam alternativas.

Para que a prática reflexiva possa se enraizar, contribuindo para a compreensãodos fenômenos educativos, segundo KEMMIS (1993) é preciso garantir certas condições no ambiente de trabalho escolar e nas relações entre o grupo de formadoresde educadores e de professores, fortalecendo ações conjuntas, projetos coletivos, capazes de modificar os contextos escolares, criando uma “comunidade crítica de professores", alimentados por de saberes acadêmicos ou profissionais construídos por outros pesquisadores ou profissionais experientes. Os saberes da prática aguçados pelo olhar investigativo e vinculados a outros saberes - "teorizar a experiência" - possibilitama formação de professores pesquisadores, aquele que não se conforma com o aluno que está em dificuldades, não se conforma que o trabalho de um ano inteiro não resulte em nenhum avanço e, pelo seu inconformismo vai batalhar, tentar outras maneiras de fazer, buscar alternativas. Esse professor, que não está registrando esse processo de investigação, de mudanças, enfim, de pesquisa é quem, de fato, está produzindo novos conhecimentos, vozes ausentes na literatura científica sobre o ensino (ZEICHNER, 1993).

\section{CURRÍCULO: CONHECIMENTO, CULTURA E PODER}

\footnotetext{
“Estudar para o professor é inseparável de seu ofício. Não há como ser bom professor sem estudar. Estudar é também e, sobretudo pensar a prática e pensar aprática é a melhor maneira de pensar certo" (Paulo Freire).
}

Nas últimas décadas do século XX os estudos sobre Currículo avançaram impulsionados por questões suscitadas no dia a dia das salas de aula e diante daincredulidade das gerações do de meados do século XX, diante de aceleradas mudanças que envolvem as populações de todo o mundo em diferentes dimensões da vida, nos colocou face aos questionamentos em relação ao conhecimento 
Os estudos sobre currículo ampliaram as pesquisas e as reflexões sobre a teoria do currículo, da sistematização das práticas fundamentadas nessas teorias e a finalidade dessas ações em relação à sociedade e à formação e desenvolvimento dos seres humanos.

Pesquisas recentes situadas no final do século XX situam os estudos sobre currículo na perspectiva cultural e resgatam a importância das investigações inerentes às práticas pedagógicas, isto é, o educador age e busca respostas, ao mesmo tempo em que investiga as razões da boa aula ou do fracasso, experimenta as hipóteses que levanta entre uma aula e outra. Na necessidade de dar respostas imediatas aos problemas e velocidade e sobrecarga cotidiana do seu trabalho, mal consegue repensar suas ações, registrar e sistematizá-las para refletir sobre as hipóteses e as mudanças que introduziu no seu plano de aula.

São aspectos importantes, pois constituem saberes singulares que nascem de experiências semelhantes e resultam em experiências plurais. Compreendê-los significa avançar no processo das investigações didáticas e contribuir para melhorar as práticas pedagógicas fundadas em teorias respondam aos desafios colocados para o $3^{\circ}$ milênio à sobrevivência e desenvolvimento da condição humana.

Assim, como já colocado, para a discussão e elaboração do documento Curricular preliminar retomaremos as ações desenvolvidas no Programa de Formação Continuada de Professores da Rede Municipal de Ensino de Carapicuiba/SP no decorrerde 2009 a 2013. As experiências decorrentes das discussões, estudos e pesquisas desenvolvidos pelos professores integrantes do Grupo de Estudos Curriculares (GEC) no processo de elaboração do Plano Curricular e os encontros de Formação Continuada com foco e Currículo (2012 e 2013) subsidiarão as práticas pedagógicas inovadoras, possibilitando compreender melhor as concepções que permeiam o Projeto Político Pedagógico. Além disso, propiciará uma experiência singular de reflexão dessas práticase o seu processo de apropriação, isto é, reflexão sobre a prática e a implantação do um Projeto de Educação da Cidade de Carapicuíba/SP, em busca de sua própria identidade.

\section{CURRÍCULO - TRAJETÓRIA HISTÓRICA E FUNDAMENTAÇÃO DO TRABALHO NOMUNICÍPIO DE CARAPICUÍBA}

As profundas transformações pelas quais passam as sociedades atuais suscitam mudanças típicas de uma forma de pensar e conceber a vida absolutamente nova. Se o desenvolvimento humano é resultante dessas transformações, o lugar da educação e da escola merece atenção redobrada e urgente, pois é o lugar privilegiado onde se aprendea aprimorar o processo de humanização. Afinal desse processo dependerá a sobrevivência da espécie humana. 
Na abordagem histórica, segundo Tomaz Tadeu da Silva (2005), teoria pressupõe "descoberta" do "real", uma correspondência entre a "teoria" e a "realidade". Ela é uma representação, uma imagem, um reflexo, um signo de uma realidade que - cronologicamente, ontologicamente - a precede.

Em diferentes momentos e em diferentes teorias, o currículo tem sido definidopelas teorias de acordo com as finalidades da educação na organização das sociedades.

Teorias tradicionais, como representadas por John Franklin Bobbitt em seu trabalho de 1918, "The curriculum", define o funcionamento da escola como uma empresa, especificando e medindo os resultados a obter, buscando eficiência baseada numa administração científica. Opondo-se a esse posicionamento, as teorias críticas do currículo questionam as produções e impulsionam as pesquisas: Quais questões a "teoria do currículo" ou um discurso curricular buscam responder? Qual conhecimento deve ser ensinado?

As teorias desenvolvem critérios de seleção que justificam a resposta que darão àquela questão, então, o currículo é sempre o resultado de uma seleção: a partir de um universo mais amplo de conhecimento e saberes, seleciona-se aquela parte que vai constituir o currículo. Porém, a discussão gira em torno de que tipo de conhecimento e apartir de que tipo de pessoas e sociedades ideais se quer.

Para os teóricos da tendência crítica, o conhecimento que se constitui é o que somos e o que nos tornamos, portanto, é a nossa identidade. A essa centralidade da questão, acrescenta-se o currículo como poder, que seleciona, privilegia determinados conhecimentos e destaca uma identidade.

No contexto mais amplo de grandes transformações sociais que envolveram diferentes dimensões das sociedades século XX e, em consonância com as transformações de meados do século, surgiram os questionamentos sobre o pensamentoe a estrutura educacional tradicionais, dentre eles, o educador Paulo Freire. O conhecimento da forma tradicional passou a ser questionado e o seu lugar repensado a partir das novas pesquisas - quais são os saberes que a criança já traz? Quais são os saberes necessários e ou importantes para serem ensinados na escola? Quais são os referenciais e os critérios que definirão o que é importante?

Essas questões foram colocadas aos professores da Rede, desde 2009, nos Encontros de Formação Continuada de Professores (EnFoCo), realizados pela SecretariaMunicipal de Educação, sempre no mês de julho. Desde sua primeira edição, a reflexão sobre os saberes escolares e a práxis cotidiana do professor pautaram os trabalhos e aliados às mais recentes pesquisas subsidiaram a gradativa construção das bases para a elaboração de um currículo próprio, pensado pelos professores 
que dia a dia trabalham diretamente com a população e conhecem a história e as particularidades do município.

Portanto, um currículo democrático que visa a humanização de todos deve ser desenhado por todos, principalmente com a participação da população que, frequentemente, é excluída dessas discussões:

\begin{abstract}
A humanização se refere, assim, ao desenvolvimento da cultural pelo qual, passa a espécie. [...] é função do momento históricopelo qual passa a humanidade e do quanto cada País participa do acervo da cultura, tecnologia, ciências e bens disponíveis a um momento dado. Dentro de um mesmo país, a participação é definida também em termos de classes sociais, etnias, gênero e diversidade biologia. (LIMA, 2008, p. 18).
\end{abstract}

Nessa perspectiva é que a Secretaria Municipal de Educação de Carapicuíba ousou desenvolver em suas escolas um projeto curricular fundamentado em teorias interacionistas de Currículo, buscando reinventar a identidade de Rede Municipal de Ensino, com um Projeto Político Pedagógico que valoriza a realidade e a cultura local, além de estimular o prazer de aprender. Assim, o Plano Curricular foi organizado em consonância com os princípios norteadores do Projeto de Educação do Município, compreendendo os espaços educativos como formadores da identidade ativa e solidária por meio da convivência, fundada em valores essenciais à coexistência enquanto seres humanos ao mesmo tempo em que busca, no espaço escolar, o desenvolvimento das potencialidades, da reflexão, enfim, aprendizagens necessárias para atuar em uma sociedade em constante transformação.

Nesse processo, realizou-se uma avaliação diagnóstica inicial no decorrer de 2009 a 2011 para subsidiar a elaboração do Plano Curricular e, em seguida, a partir da concepção de Currículo como conhecimento essencial, repensar as estruturas do sistema; retomar conceitos norteadores como o que é conhecimento, abordagem metodológica e avaliação; reorganização das disciplinas em áreas do conhecimento, determinando a seleção e distribuição dos conteúdos o que demandaria também a reorganização dos tempos e espaços escolares.

A construção de um Projeto desse porte envolveu a seleção de conhecimentos evalores que fundamentam a formação de crianças e jovens no momento histórico da escolha de que humanidade se quer ao mesmo tempo em que se mantém as características que identificam o perfil do sistema de ensino e que lhe possibilite ressignificar e recriar a identidade das escolas públicas na cidade de Carapicuíba.

Buscou-se, portanto, construir um currículo que pudesse dialogar com as experiências anteriores ao mesmo tempo em que estimulasse a interação para possibilitar a emergência do novo. 
Para tanto, as reflexões no campo da pesquisa didática tornaram-se também essenciais. Ana Sílvia Moço Aparício, da Universidade Municipal de São Caetano do Sul (USCS, Brasil) indica que "os registros de sala de aula, tais como os relatos reflexivos, também são considerados objetos e dados de análise essenciais"”3 para esse trabalho. A importância desse procedimento reside no fato de que desloca o foco da pesquisa para as práticas em sala de aula:

É necessário realizar investigações didáticas que permitam estudar e validar as situações de aprendizagem que propomos, aperfeiçoar as intervenções de ensino, apresentar problemas novos quesó se fazem presentes na sala de aula. (LERNER, 2002:43).

As investigações didáticas propiciam aos professores levantarem hipóteses acerca do que acontece na sala de aula, situando os problemas na dinâmica do espaço que o originou. Ao mesmo tempo, possibilitam observação e acompanhamento direto nopróprio processo da prática. Na medida em que o professor observa, investiga a sua própria prática e, delas retira elementos fundamentais para análise e reflexão.

\section{A IMPORTÂNCIA DA REFLEXÃO SOBRE O ENSINO E A APRENDIZAGEM}

A sala de aula é um espaço por excelência de produção de significados e por isso é tão importante o estudo do processo de ensino e aprendizagem em sua multidimensionalidade, articulando-as. A dimensão humana na relação interpessoal é o centro dos processos de ensino e aprendizagem enquanto se reveste de intencionalidade quando sistematiza as ações e organiza as condições que propiciam a aprendizagem na dimensão técnica, mas ela se realiza na dimensão político-social, na especificidade da organização social, pois dela emergem as práticas pedagógicas significativas.

Só transformamos as informações em conhecimento quando há um significado atrelado à nossa própria experiência. Quando o conhecimento é significativo contribui para a superação das dificuldades do dia a dia. Não basta introduzir materiais didáticoschamativos, com muitos desenhos e cores; é fundamental que o professor saiba para quee em que circunstâncias utilizá-los.

Baseado na concepção de que se aprende para ensinar e ao ensinar, se apropria do conhecimento, o currículo propõem-se trabalhar em todas as áreas do conhecimento, habilidades comuns no projeto. Para tanto, as áreas de conhecimento foram organizadas a partir dos objetivos comuns para a formação do aluno, os conhecimentos que compartilham os mesmos objetos de estudos, propiciando o diálogo necessário para o desenvolvimento de uma prática escolar em uma perspectiva integradora e crítica. 
A proposta metodológica interdisciplinar e a indicação de eixos comuns para o desenvolvimento de competências e habilidades buscam a superação do ensino compartimentalizado e a fragmentação do conhecimento, na convergência de ações de todas as áreas, como:

- pesquisar/investigar

- saber problematizar a realidade como abordagem metodológica comum

- quebrar/superar preconceitos

- compartilhar descobertas, investigações, dúvidas, conhecimento, bibliografia, etc.

- trabalhar coletivamente

- desenvolver valores (ética e moral)/espiritualidade (transcendência)

- ler, escrever e produzir diferentes textos como responsabilidades de todosna escola

- mobilizar informações, conceitos e procedimentos em situações diversas

- valorizar a cultura local e do aluno

- utilizar relatos de prática mediando a compreensão do que pensam efazem os professores para aproximar do Currículo que se propõe.

A distribuição de conteúdos, respeitando-se as necessidades de aprendizagem, desenvolvimento dos alunos e as especificidades locais (escola e realidade local), segue os Referenciais e Parâmetros Curriculares Nacionais, no que diz respeito aos conteúdos mínimos, pois nele se funda a formação integral e a construção conjunta do conhecimento, possibilitando compartilhar saberes e experiências, ao mesmo tempo em que se estimula a elaboração de projetos de trabalho e se corresponsabiliza as equipes

escolares na construção dos novos saberes. Constituem também, conteúdos de ensino,as aprendizagens de valores e atitudes na formação de posturas como aluno, cidadão e ser humano.

Essas novas formas de organização suscitaram novas demandas, como repensaras condições propiciadoras das aprendizagens, o que requereu metodologias distintas, novas formas de ocupação e distribuição dos espaços e dos tempos, diferentes agrupamentos, priorizando-se o pedagógico, por exemplo, na distribuição das disciplinas na grade horária, respeitando-se as necessidades de tempo/aula para projetos ou trabalho coletivo.

Apesar da complexidade e dificuldades no processo de elaboração do Plano Curricular é preciso ter clareza conceitual porque os conflitos que permeiam este processo envolvem relações de poder de variados níveis. 
Para a educadora e pesquisadora Elvira de Souza Lima (2008), um currículo humanizador introduz sempre novos conhecimentos não se limitando aosconhecimentos relacionados às vivencias ou às realidades regionais. Um currículo democrático deve, portanto, possibilitar que todas as pessoas tenham acesso aos bens culturais e ao conhecimento. Dessa forma, o tempo escolar foi organizado de tal forma que os conteúdos escolhidos para serem ensinados fossem distribuídos no decorrer de um ano letivo e longo da escolarização, de modo a superar gradativamente a fragmentação e propiciar aos alunos a compreensão e a apropriação dos conceitos que lhes possibilite apreender as vivências cotidianas e ir além.

$\mathrm{Na}$ atualidade muito se tem discutido sobre a interdisciplinaridade como afórmula mágica para superar a fragmentação do conhecimento.

Como a interdisciplinaridade é um processo - uma abordagem metodológica - existem várias linhas de ações de acordo com os desafios a serem superados e os encaminhamentos adotados pela equipe escolar, de preferência uma decisão tomada coletivamente respeitando-se a "pluralidade dos espaços e das épocas e a multiplicidade das formas do humano [...]” (GUNSDORFF, apud SANTOMÉ, 2002, p. 66). Esse é o caminho em construção em Carapicuíba.

\title{
7 A AVALIAÇÃO REALIMENTA O PROCESSO
}

\begin{abstract}
A avaliação é reconhecida como um dos pontos privilegiados para estudar o processo de ensino-aprendizagem. Abordar o problema da avaliação supõe necessariamente questionar os problemas fundamentais da pedagogia. Quanto mais se penetra no domínio da avaliação, mais consciência se adquire do caráter enciclopédico de nossa ignorância e mais se põe em questão nossas certezas, ou seja, cada interrogação colocada leva a outras. Cada árvore enlaça com outra e a floresta aparece como imensa (CARDINET, 1986, Apud SACRISTÁN e GÓMEZ, 2007, p. 295).
\end{abstract}

Para HOFFMANN ${ }^{3}$ é possível uma escola desenvolver uma cultura avaliativa mediadora contrapondo à avaliação classificatória e excludente, partir de três princípios:

$1^{\circ}$. Avaliação a serviço da ação: toda a investigação sobre aprendizagem busca superar as dificuldades e melhorar a aprendizagem.

$2^{\circ}$. Avaliação como projeto de futuro, que reflete sobre os resultados da avaliação para transformá-los em propostas pedagógicas que atendam as necessidades dos alunos.

$3^{\circ}$. Avaliação baseada no princípio ético claro, com parâmetros de qualidade estabelecidos pelo coletivo da escola norteada por uma proposta político-pedagógico definida com clareza para que a prática avaliativa seja coerente e, efetivamente promova o atendimento aos alunos com maiores dificuldades.

\footnotetext{
${ }^{3}$ Entrevista disponível em < http://www.dn.senai.br/competencia/src/contextualizacao/celia\%20\%20avaliacao\%20Jussara\%20Hoffmam.pdf>, acesso em 02.11.2013.

crescimento, de desenvolver possibilidades para que os sujeitos realizem aprendizagens vida afora, de socializar experiências, de perpetuar e construir cultura". (FERNANDES, 2008, p. 23); avaliação da instituição sob responsabilidade coletiva dos profissionais norteada pelo projeto pedagógico da escola; e a avaliação do sistema escolar sob a responsabilidade do poder público face a um projeto político.
} 
Nesse sentido, a avaliação deve se voltar para as múltiplas perspectivas tanto da organização social, quanto das diferentes dimensões em que ação social resulta em mudanças. Mais especificamente, a educação escolar.

Quaisquer que sejam os procedimentos, a avaliação é necessária. Segundo FERNANDES (2008), as práticas de avaliação devem ser coerentes com a concepção deaprendizagem; de educação e de escola, ocorrendo como ação coletiva de formação em várias esferas e com objetivos distintos: a avaliação de aprendizagem dos alunos sob responsabilidade do professor e promotora de princípios “de incluir, de promover No processo de construção do conhecimento o conflito que se estabelece desvela as múltiplas perspectivas do olhar e dos interesses pela hegemonia na escolha do currículo. Porém, é possível avaliar com pressupostos que levem em conta esse processo de construção do conhecimento, isto é, uma concepção de currículo que busca aprimoramento no processo de humanização.

A avaliação formativa, proposta no Projeto de Carapicuíba, busca, em última instância, "a tomada de consciência que ajuda a refletir sobre um processo, insere-se no ciclo reflexivo de investigação na ação: planejamento de uma atividade ou plano, realização, conscientização do ocorrido, intervenção posterior.” (SACRSITÁN e GÓMEZ, 2007, p. 328). É nesse contexto que se deve inserir a avaliação dos conteúdos escolares mais específicos (matéria, disciplina, conteúdos programáticos), atendendo ao mesmo tempo, o desenvolvimento e valorização da autonomia e da capacidade de criar e, apropriar-se do conhecimento sistematizado.

Como os instrumentos de avaliação são diversos é preciso, portanto, estar atento para o seu planejamento e elaboração. FERNANDES (2008) chama a atenção para alguns aspectos importantes e que pautam o documento preliminar em discussão pelos professores de Carapicuíba:

a. A linguagem a ser utilizada: clara, esclarecedora, objetiva;

b. A contextualização daquilo que se investiga; não perde ofoco do que se quer saber e evitar interpretações;

c. O conteúdo deve ser significativo para quem está sendoavaliado;

d. Estar coerente com os propósitos do ensino;

e. Explorar a capacidade de leitura e de escrita, bem como oraciocínio.

\section{CONSIDERAÇÕES}

Em 2013, o Grupo de Estudo Curricular (GEC), formado especialistas das diversas áreas do conhecimento, gestores e professores da Rede de Ensino de Carapicuíba, se reuniu mensalmente, por 
áreas do conhecimento/disciplinas para aprofundar os estudos sobre os fundamentos do Currículo e das disciplinas escolares, metodologias e formas de avaliação tendo como base planos de ensino e atividades desenvolvidas nas escolas. As reflexões ora apresentadas são fruto do trabalho desses grupos e da equipe pedagógica que assessora o projeto e parte do processo de construção do currículo do município.

Para 2014, estão previstas ações que darão continuidade ao trabalho, quando o documento preliminar elaborado pelo GEC será apresentado à Rede e discutido em cadaescola. Em cada componente curricular foi indicado um professor ou gestor participante para acompanhar a reflexão e implementação nas escolas e colher material para a análise e elaboração do documento final com as Diretrizes Curriculares do Município. Nesse ano também ocorrerão as eleições para diversos cargos dos poderes Executivo e Legislativo, em todo o país, ampliando a importância da discussão pedagógica e políticasobre o currículo a ser implantado para toda a população atendida pelas escolas jurisdicionadas na Secretaria de Educação do Municipio de Carapicuiba. 


\section{REFERÊNCIAS}

BRASIL, Secretaria de Educação Fundamental. Parâmetros curriculares nacionais. Secretaria de Educação Fundamental. Brasília: MEC/SEF, 1997.

BRASIL. Ministério da Educação. Secretaria de Educação Básica. Diretrizes curriculares nacionais para a educação infantil. Secretaria deEducação Básica. - Brasília: MEC, SEB, 2010.

CARAPICUÍBA. Histórico do Município. Disponível em: www.carapicuiba.sp.gov.br/index.php/carapicuiba/historico, acesso em 27.11.2013.

CARDOSO, B. Da necessidade de humanizar os dados quando se trata de educação... Rio de Janeiro: Trabalho e Sociedade - Ano 2 - No 4. Ago. 2002. P. 17 a 21.

CHARLOT, B. Da relação com o saber: elementos para uma teoria. PortoAlegre: Artmed, 2000.

Fernandes, D. Avaliar para aprender: Fundamentos, práticas e políticas. SãoPaulo: Editora UNESP, 2008.

FREIRE, P. Pedagogia da Autonomia: saberes necessários à práticaeducativa. 15. ed. São Paulo: Paz e Terra, 2000.

GIROUX, H. Os professores como intelectuais. Porto Alegre: EditoraArtmed: 1997.

HERNANDEZ, F. e VENTURA, M. A organização do Currículo por projetos de trabalho. Porto Alegre: Artes Médicas. 1998.

HOFFMANN, Jussara. Avaliação mediadora: uma prática em construção dapré-escola a universidade. Porto Alegre: Mediação, 2009.

. Pontos e contrapontos: do pensar ao agir em avaliação. Porto Alegre: Mediação,

2007.

KEMMIS, S. La Formación del Profesor y la Creación y Extension de Comunidades Críticas de Profesores. In: Investigación en la Escuela, nº 19, pp.15- 38, Sevilha, Espanha, 1993.

LERNER, D. Ler e escrever na escola: o real, o possível e o necessário.

Porto Alegre: Artmed, 2002.

LIMA, E.S. Indagações sobre currículo: currículo e desenvolvimento humano. Brasília: Ministério da Educação, Secretaria de Educação Básica, 2008.

MOREIRA, A. F. B.; GARCIA, R. L. Currículo na contemporaneidade- incertezas e desafios, São Paulo: Cortez, 2004.

MOREIRA, A.F.; SILVA, T.T. Currículo, Cultura e Sociedade. $4^{\text {a }}$ ediçãoSão Paulo: Cortez, 2000.

MORIN, E. Os sete Saberes Necessários à Educação do Futuro. 3a. ed. -São Paulo: Cortez, 2001. NÓVOA, A.(org.) Os professores e sua formação. Lisboa: Ed. DomQuixote, 1992. 
PERRENOUD, P. Pedagogia Diferenciada: das intenções à ação. PortoAlegre: Artmed: 2000.

REVISTA GESTÃO ESCOLAR, Nov. 2001, "Os nove jeitos mais comuns de avaliar os estudantes e os benefícios de cada um. Disponível em http://revistaescola.abril.com.br/planejamento-eavaliacao/tabela_avaliacao_024.html, acessado em 20/11/2013).

REVISTA NOVA ESCOLA, edição 191, Abr. 2006. Entrevista comCipriano Carlos
Luckesi.
Disponível
em

http://revistaescola.abril.com.br/planejamento-e-avaliacao/avaliacao/cipriano-carlos-

luckesi-

424733.shtml, acessado em 20/06/2010.

SACRISTÁN, J.G.; GÓMEZ, A.I.P. Compreender e transformar oensino. Porto Alegre: Artmed, 2007.

SANTOMÉ, J.T. Globalização e Interdisciplinaridade: o currículointegrado. Porto Alegre: Artmed: 2002.

SILVA, T.T. Documentos de Identidade: uma introdução às teorias docurrículo. São Paulo: Autêntica, 2005.

TARDIFF, M. Saberes docentes e formação profissional. Petrópolis, RJ:Vozes, 2002.

THURLER, M.G. Inovar no interior da escola. Porto Alegre: Artmed, 2001.

ZEICHNER, K.M. A formação reflexiva de professores: ideias e práticas. Lisboa: Educa, 1993. 